\title{
REYES Y ESTRADA, LA URDIMBRE DISCRETA
}

Los tres volúmenes de la correspondencia de Alfonso Reyes y Genaro Estrada, Con leal franqueza ${ }^{1}$, muestran con amplitud las características generales del epistolario completo de Reyes y, simultáneamente, desvelan los rasgos particulares de una relación afectiva que llegó a la intimidad. Entre los aspectos generales que tienen especial importancia dentro del epistolario conjunto destacan: el intercambio de información; la pseudo conversación a distancia; el espacio para el desahogo personal; el apunte apresurado que más tarde se recuperará dentro de una dimensión literaria; la semblanza a contraluz del corresponsal y la conformación de una urdimbre informativa básica para la historia cultural de Hispanoamérica. Distinciones menores son: los gestos de cortesía y la voluntad de apoyo y servicio, que se convierten en elementos de cohesión. Entre las características particulares dentro de la co-

${ }^{1}$ Edición de Serge I. Zaïtzeff, El Colegio Nacional, México, t. 1 (1916-1927), 1992, 485 pp.; t. 2 (1927-1930), 1993, 290 pp., y t. 3 (1930-1937), en prensa, 417 cuartillas. Agradezco al editor Zaïtzeff y al secretario administrativo de El Colegio Nacional, licenciado Fausto Vega, las facilidades para consultar el original del libro que está actualmente en prensa. En las citas abreviaré la referencia a esta edición: $C L F$; en las notas abreviaré Alfonso Reyes: AR. A lo largo de todo el trabajo aludiré tanto a los Obras completas de Reyes (F.C.E., México, 1955-1994): OC, seguidas del tomo que manejo, así como a los siguientes epistolarios de Reyes; entre los publicados: Pedro Heríquez Ureña, Julio Torri, José Vasconcelos, Mariano Silva y Aceves, Antonio Castro Leal, Martín Luis Guzmán, Victoria Ocampo, Válery Larbaud; entre los inéditos: Enrique Díez-Canedo, José Ortega y Gasset, Enrique González Martínez, Francisco Castillo Nájera, Rafael Cabrera, los hermanos Francisco y Ventura García Calderón, Jorge Mañach y Luis Alberto Sánchez, ellos consultados en la Capilla Alfonsina gracias a la generosidad de Alicia Reyes. De éstos hice una selección que puede ser ilustrativa: "Cartas entre AR y escritores peruanos", en Saludo del Perú para AR, ed. y comp. de Rafael Vargas, Embajada de México en el Perú, Lima, 1989, pp. i-xxvi. En mi trabajo referido infra, n. 11, abundo en detalles sobre esta correspondencia. 
rrespondencia con Estrada sobresalen: las acotaciones y reconsideraciones sobre el servicio diplomático mexicano, sobre la vida cultural latinoamericana, y en especial la mexicana, y sobre las formas de realizar el trabajo oficial y las condiciones en que éste se ejecuta. Sobre estos aspectos versarán las siguientes páginas².

\section{LOS DATOS, CORTINA DE UNA METÁFORA}

El intercambio de información cimenta el valor parafernárico ${ }^{3}$ del espistolario (y del Diario, cabe añadir) de Alfonso Reyes, altamente apreciado por los familiarizados con su obra. A través de él ha sido posible penetrar en su persona, en las tareas literarias y de servicio que realizó o con las que estuvo vinculado, en su tiempo, en los lugares por donde transcurrió su vida y en las circunstancias

2 El 3 de marzo de 1994, en la Capilla Alfonsina, El Colegio Nacional y la Dirección de Literatura del INBA convocaron a José Luis Martínez, Alfonso Rangel Guerra, Fernando Curiel y a quien esto escribe a dialogar públicamente sobre el epistolario que ahora me ocupa. El Colegio conserva esas notas y JosÉ LuIS MarTínez publicó las suyas en Vuelta, 1994, núm. 210, pp. 51-52. Lo que ahora presento es una versión distinta a lo entonces expuesto en forma libre a partir de un esquema centrado en los asuntos diplomáticos.

${ }^{3}$ José Bianco indica respecto al concepto: "La expresión parafernaria, que viene del griego, se usa en inglés con la acepción de cosas accesorias, paraphernalia, pero en francés y en español conserva su significado original: es el patrimonio que le corresponde a una mujer casada fuera de la dote. En francés, $p a-$ raphernal, en español, paraferna... La obra [literaria] propiamente dicha sería la dote: los bienes parafernales serían los diarios literarios, las memorias, las cartas. En ocasiones, esta así considerada obra accesoria, esta obra alrededor de una obra, puede ser la obra única, o, para algunos, la obra casi principal de un escritor". Bianco emplea el concepto en función de una distinción fundamental: entre la parafernaria y la obra literaria propiamente dicha se alcanza a delinear la invisible frontera entre el yo cotidiano y el yo creador que es en sí mismo el hombre de letras; entre la vida pública y la vida privada del artista. Su conclusión es significativa, más a contraluz del epistolario de Reyes y Estrada: "Creo que los diarios de escritores, las cartas, las memorias, pertenecen a un género literario que sobrevive. Una cantidad de factores de índole social, económica y política inciden desfavorablemente sobre un género que por definición es privado, casi secreto. Hasta en épocas de despotismo, muchos escritores se defendían de ese régimen conservando mediante diarios y memorias una suerte de libertad personal o de ilusión de libertad. El destino vacilante de la literatura tiene mucho que ver con la enajenación del mundo y la creciente disminución de la individualidad. El mundo humanista es el resultado de un grupo de hombres que pensaron individualmente" ("Parafernaria" [1984], en Ficción y reflexión. Una antología de sus textos, prel. de J. L. Borges, F.C.E., México, 1988, pp. 272-275). 
en que ocurrieron algunos incidentes. Aunque considerado "instrumento de trabajo", "esqueleto" o "andamiaje" informativo -indica Alfonso Reyes Mota en la presentación del Diario de su padre-, la parafernaria descubre detalles (triviales en su apariencia) indispensables para entrar con paso más seguro al mundo literario, a la labor cultural y a la actividad de servicio de don Alfonso.

Sin embargo, para el lector común la importancia parafernárica se desvanece: la mayoría de las cartas dirigidas a sus amigos, incluidos los más entrañables — como Pedro Henríquez Ureña, Julio Torri o Genaro Estrada-, resultan poco "sabrosas", o "sustanciosas", o "literarias", o cualquier otro calificativo que provoque el apetito del lector. Ni el epistolario, ni menos aún el Diario, están concebidos para hacerse públicos, ni pensados para la posteridad ${ }^{4}$. Por eso será imposible encontrar arengas y críticas políticas como las de Cicerón, reflexiones y propuestas éticas como las de Séneca o apostillas y descripciones sobre la vida mundana y privada de una época y lugar como las de Mme. de Sevigné, por citar tres ejemplos que Reyes consideraba paradigmáticos dentro de la literatura epistolar ${ }^{5}$.

En dirección contraria, dispersas y fragmentadas, hay indiscreciones - pocas y cifradas-, sátiras — de buena fe, en la casi totalidad de las ocasiones, pues don Alfonso era tan discreto que ni en la privacidad epistolar ofendía-, confidencias - escasas, pero jugosas-, reconsideraciones de varia índole — aunque las mejores las dejaba para su obra literaria- y, con una abundancia agobiante, datos, fríos, secos, inhóspitos, pero fundamentales para el especialista. Todos estos fragmentos atomizados dentro de los varios millares de cartas y de cuartillas del Diario, adquieren sentido y significado tras la reelaboración articulada de las piezas dentro del conjunto de la obra completa y a la luz de la biografía del propio Reyes y de sus corresponsales ${ }^{6}$.

En este punto, la correspondencia de Reyes y Estrada resulta valiosa. Con ella se puede reconstruir una parte básica de las condiciones en que don Alfonso realizaba sus actividades diplomáticas y de los propósitos y alcances de sus tareas —-siempre ligadas

${ }^{4}$ Con malicia, Reyes dejó revoloteando ciertos ribetes que consideraba significativos para un mejor conocimiento de su obra literaria, sus tareas de servicio y su persona. Véase infra, n. 14.

${ }^{5}$ Cf. AR, "Literatura epistolar" [1949], OC, t. 25, pp. 477-489.

${ }^{6}$ Un ejemplo magistral del buen empleo de este tipo de información se encuentra en la "Presentación" de Ernesto Mejía Sánchez al t. 21 de las OCo en Alfonso Rangel Guerra, Las ideas literarias de AR, El Colegio de México, México, 1989. 
a las de Estrada y a las de México. Para las actividades hay un ejemplo notable: la menudencia cotidiana de una Legación o Embajada, por lo común desdeñada por su insignificancia y, por lo mismo, muy difícil de documentar. En las cartas, la morralla de servicio diplomático adquiere un valor universal; de hecho, la instalación y las instalaciones de las residencias oficiales de la representación mexicana en Francia, Argentina y Brasil se convierten en un asunto de tales proporciones que se transforman en las grandes protagonistas del epistolario, tanto que las pormenorizadas descripciones de los edificios y sus habitantes consituyen fragmentos literarios dignos del más refinado absurdo, aunque sólo sea el retrato hiperrealista de la burocracia, su dinámica y sus consecuencias tras años de inercia acumulada.

Lo que encierra esta aparente nimiedad se vuelve representativo dentro del proceso de construcción de las instituciones gubernamentales de México: hombres como Alfonso Reyes, Genaro Estrada y muchos más de su generación asumían la responsabilidad institucional como un compromiso personal; desempeñaban tareas cuyo espectro abarcaba desde intendente de la residencia oficial - Reyes describe con puntual y lastimosa minucia los problemas que se desprenden de estos niveles- hasta representante plenipotenciario ocupado de los asuntos de Estado - cuya descripción, lamentablemente, no queda registrada con la amplitud que el especialista desearía. Es decir, en los años veinte y treinta, entre las cualidades de unos diplomáticos como Reyes y Estrada debía existir la doble condición del hombre de Estado suspicaz y discreto, y del servidor de oficio múltiple y dispuesto a sobrellevar los horrores de la burocracia en su más pura y despreciable acepción.

Los problemas de la instalación y las instalaciones de la residencia oficial también son una metáfora. Entre 1921 y 1936, hombres como Reyes y Estrada, esencial y vitalmente entregados a la literatura, se dedican a concebir y construir el entramado diplomático del México posrevolucionario. El hecho no es un azar. Estrada en México (como Oficial Mayor, Subsecretario y Secretario de Relaciones Exteriores y Embajador de España) y Reyes en Madrid, París, Buenos Aires y Río de Janeiro (como representante diplomático, desde Segundo Secretario hasta Embajador), son dos de los varios (siempre escasos) protagonistas que se entregan con fervor a concebiry establecer un concepto de diplomacia riguroso, justo y pensado para el porvenir. Para ello resultaba indispensable revisar desde el desagüe de las cañerías (Reyes lo describe en forma dramática respecto a la residencia de Buenos Aires) hasta el trato con el Poder Ejecutivo 
para educarlo y normar criterios (Estrada deja entrever una sutil discreción en sus negociaciones con el presidente Calles).

El valor parafernárico del intercambio de información adquiere otra dimensión cuando, tras permitir una mejor y humana aproximación a los corresponsales, el lector puede adentrarse en el tiempo y el lugar por los que transcurre el epistolario. Entre otros, el ejemplo más notable es la relación establecida entre Estrada, Reyes y los integrantes del grupo Contemporáneos. Se ha escrito sobre el apoyo de Estrada para publicar la revista Contemporáneos y sobre el estímulo de Reyes para hacerla circular en un ámbito internacional con colaboradores de otras geografías. El epistolario ofrece información (algunos chismes e indiscreciones a vuelapluma) que ha sido varias veces explorada y analizada en función de esa revista.

Sin embargo, sobre este ejemplo hay un aspecto que se ha desdeñado o se ha dado por sobreentendido: los amigos Genaro y Alfonso creían en la palabra escrita, y más si ésta poseía cualidades literarias, pues ninguna acción diplomática trascendería más que aquella que lograse arraigar en la Inteligencia de los países; "nuestra América" (Martí, Darío, Rodó) existirá sólo a partir de la lengua común, y el arte es lo único que no tropieza con trámites fronterizos ni trabas arancelarias. En otras palabras: ambos reconocían la calidad literaria de los Contemporáneos (en el temprano 1924 coinciden en su opinión sobre Villaurrutia: será un gran poeta, escriben), pero valoraban más el uso de la revista para propósitos de acercamiento e intercambio cultural ${ }^{7}$.

\section{ESCRIBIR, SUCEDÁNEO DE LA CONVERSACIÓN}

En el epistolario de Alfonso Reyes la pseudoconversación a distancia se distingue por una figura recurrente: la lejanía. Él, pese al lugar

${ }^{7}$ Esta concepción de intercambio y acercamiento se puede rastrear en otros ejemplos que surgieron a la par de Contemporáneos y, sobre todo, tras su desaparición. Reyes está cerca de colecciones editoriales y revistas argentinas entre 1927 y 1930 y entre 1936 y 1937; también hace su Monterrey, correo literario desde Brasil. Estrada, en Madrid, propone a algunos de la Generación del 27 para hacer una revista literaria internacional (que se ofrece a financiar) desde la España de Azaña, pero esto nunca cristaliza. Un detalle más: Reyes, por iniciativa propia o solicitud de la autoridad, interviene activamente en el establecimiento de las normas legislativas internacionales que rijan y amparen la circulación libre de la propiedad intelectual. 
común ya canonizado, no pretende "conversar" a través de su correspondencia ${ }^{8}$. Su búsqueda es más intensa y personal: aspira a paliar la ausencia del otro mediante la escritura. En dirección inversa, con sus cartas "personales", quiere cristalizar su deseo de presencia en el otro. Se lo espeta con severidad a Martín Luis Guzmán, aunque dentro de un contexto atemperante: "Yo, siempre que escribo, tengo presentes a mis ojos, como una alucinación, las caras de mis amigos. Me cuesta trabajo entender que ellos puedan olvidarse de mí, de mi corazón, al escribir o decir ciertas cosas"10. En cambio, a su entrañable Estrada le muestra su obsesión:

Dice Ud. que necesita sobre mí noticias de actividades, para defenderme llegado el caso de las maniobras de los políticos adversos, para quienes no cuenta mi trabajo intelectual [escribe Reyes en octubre de 1925 desde París]. Supongo que me lo dice Ud. como una regla y para que yo le dé cuantos elementos posea y no porque mi trabajo deje algo que desear. ¿Verdad? Pero dígamelo de todos modos. Dígame si [Aarón] Sáenz, si Ud., si [Arturo] Pani, si el presidente [Calles] están contentos del sitio que he logrado abrir aquí, del modo como trabajo, etc., etc. Si hay deficiencias, señálemelas. Mucho ganaría el trabajo quitándome agregados fantásticos $(C L F$, t. 1, p. 345).

Así, el deseo de don Alfonso es preciso: estar en los otros como éstos están en él y normarse a sí mismo a través de la imagen propia reflejada en los otros: "Soy muy sensible a la opinión". No obstante, la distancia impide su realización tanto como incrementa la doble y dolorosa noción de ausencia: ni ellos están en él ni él está en ellos. El flujo de la conversación está roto. Para atenuarlo escribe, y escribe en cantidades proverbiales, y escribe sobre lo que escribe - pues en su Diariolleva, entre otros muchos registros informativos, una puntual anotación de la correspondencia que envía y recibe.

El acto de escribir cartas se podría interpretar como la voluntad de conversar; la voluntad de hacer presente la ausencia del otro con la intención de hacerse presente en el otro. Sin embargo, esto que podría tomarse como un acto naturalmente humano,

${ }^{8}$ No obstante, después él mismo indicará que las epístolas son sucedáneos de la conversación. Cf. supra, n. 6.

${ }^{9}$ Recuérdese que hasta mediados de los años veinte escribió con su puño y letra gran parte de su correspondencia, incluso la de mero trámite protocolario para agradecer esto o aquello — no obstante haber sido un excelente mecanógrafo, como se observa en sus informes diplomáticos.

${ }^{10}$ Véase el epistolario Guzmán/Reyes, Medias palabras. Correspondencia 19131959, ed. de F. Curiel, UNAM, México, 1991, p. 134. 
en el caso de Reyes adquiere dimensiones sintomáticas de una ansiedad: llenar el vacío, romper la distancia, suplir la falta o atenuar el silencio. Es decir, la "conversación" se transmuta en la grotesca deformación del acto puro de escribir cartas; las palabras de los corresponsales se convierten en el simulacro de la conversación, lo cual se acentúa cuando se observa que el común de sus corresponsales eran francamente parcos para escribir.

El punto extremo es el "correo literario de Alfonso Reyes", Monterrey (1930-1938), suma y síntesis pública del epistolario "privado". El simulacro de conversación cristaliza en la propuesta de comunicación (hacer común algo). Asimismo, canaliza su compulsiva ansiedad por escribir cartas hacia el verdadero y siempre velado propósito de paliar la distancia, disminuir su ausencia y fortalecer su presencia; con su "correo literario" atenúa la lejanía respecto a ese "todo" que vive durante su estancia en Río de Janeiro. Sin embargo, en el segundo número de Monterrey surge un tropiezo privado que repercute en lo público: su eterno preceptor, Pedro Henríquez Ureña, le reprueba estar perdiendo su tiempo y talento en un "correo literario" inútil (pues nunca comprende el concepto de utilidad otorgado por Reyes a su publicación periódica). La sacudida es violenta. La inseguridad súbitamente cobra cuerpo y exige respuestas: consulta por vía telegráfica a Genaro Estrada, quien desde Madrid y con otro escueto telegrama ("Debe usted continuar...") reconoce que su tarea tiene algún valor y sentido.

Así se vuelve al principio enunciado: su correspondencia es una pseudoconversación. Lo privado desaparece en aras de lo público; las cartas manuscritas, instrumentos indispensables para el vínculo personal, devienen páginas impresas distribuidas por centenas. En todo ese mar de epístolas y páginas del Diario, el lector especializado siente estar ante un náufrago a la deriva de su propia soledad. En forma simultánea asoma la antípoda: la voluntad del náufrago por llegar a tierra firme provoca una verdadera admiración. Reyes, en su intimidad (y en particular durante los años treinta, cuando suma poco más de cuarenta de edad), se reconoce solo ante su propia y humana pasión como escritor, la cual confronta y lo confronta con su "servicio obligatorio" a México. Su disyuntiva es rotunda: recuperar la libertad del creador literario como la vivió en Madrid hacia el final de la segunda década del siglo o proseguir con una labor civilizadora y de servicio como la que realiza en los treinta ${ }^{11}$.

${ }^{11}$ En otra oportunidad desarrollé más ampliamente estas ideas. Cf. "La raya 
El medio millar de cartas intercambiadas entre Reyes y Estrada revela otra cualidad identificable en el epistolario completo. Don Alfonso desea proporcionar información a su amigo; algo similar hace con los pocos corresponsales confidentes, a quienes externa sus puntos de vista y muestra su agudeza analítica. Sabe que la información sirve para que el otro esté enterado y pueda normar criterios; son descripciones o enumeraciones en las que procura cierto "alejamiento" para ponderar mejor su análisis e interpretación ${ }^{12}$. En sentido inverso, desata la recreación con un afán festivo, como ilustran la escasa docena de breves y lacerantes viñetas dispersas a lo largo de sus veinte años de amistad con Estrada, quien se las celebra y aun comparte con personas como Plutarco Elías Calles, a quien lee cartas completas. Un ejemplo ante el espejo:

Genaro: tengo 40 cumplidos [escribe desde Argentina en 1930]. Sigo haciendo libros. Voy publicando los de cinco o diez años atrás: tan cargado voy. Mi mujer empieza a cansarse de fregar suelos en la Embajada y de ser mayordomo de una casa cara y absurda. Sus nervios y mi felicidad padecen por culpa de Barona [empleado de la Cancillería]. Mi hijo va a cumplir 17 años, y ya me cuida los ojos cuando se me van detrás de las mujeres. Mis jaquecas son suaves, pero continúan. Todavía se me para. He servido lealmente a mi país: no le he hecho daño en el extranjero. Estoy muy pobre. No he ahorrado nada, y los hombres y los gobiernos cambian. No puedo dar un braguetazo de quince mil argentinos, por más que hago. No estudié a tiempo las artes de la padrotería. Sólo un "batacazo" en el Hipódromo puede salvarme. Pero confiar en los cascos ligeros de los caballos es peor que en los de las mujeres. Tal es el dolor de su amigo... (CLF, t. 2, p. 244).

indecisa", en Voces para un retrato. Ensayos sobre AR, comp. V. Díaz Arciniega, UNAM-F.C.E., México, 1990, pp. 39-67.

$12 \mathrm{El}$ ejemplo por antonomasia se encuentra en los informes periódicos que debe rendir el representante diplomático a la autoridad. Aquí, la voluntad de "objetividad" alcanza su más alta y refinada expresión y descubre a un Reyes analista político francamente suspicaz y certero. Cf. AR, Misión diplomática. Informes y correspondencia del embajador, ed. V. Díaz Arciniega, F.C.E.-S.R.E., México (en prensa). Con los amigos procede en forma parecida; por ejemplo, cuando describe a José Ortega y Gasset las características de la vida intelectual argentina en 1930. 
La virtual conversación a distancia implícita en la correspondencia de Alfonso Reyes se transforma en un espacio y tiempo útiles para el desahogo personal. En las contadas ocasiones en que aparece, muestra algunas variantes, que van desde el ribete al aire ${ }^{13}$, hasta la explosión tumultuosa de emociones acumuladas a lo largo de años. Entre los extremos del gesto menor y del aluvión instantáneo quedan momentos personales reveladores de una intimidad cuya ebullición socavaba la imagen de solidez y entereza que mostraba en su vida pública.

Los "flecos sueltos" 14 se hacen patentes en innumerables gestos dispersos en su correspondencia y Diario. Pulverizados, su importancia se atenúa hasta la casi desaparición; quedan como expresiones incidentales descontextualizadas. Sin embargo, concatenados y articulados, adquieren un sentido humano significativo y, sobre todo — si vemos en el caso único de su correspondencia con Estrada-, representativo de una larga serie de preocupaciones e incomodidades vitales - muchas de ellas centradas en asuntos en apariencia nimios. El listado abruma y se desprende de los asuntos sobre los que él desliza apostillas: el horror a los jefes y a la burocracia; la pérdida de tiempo, talento y recursos en asuntos "ratoneros"; el caos doméstico; la aparente contradicción entre el deber y el querer, o entre el servicio público y la literatura; el deseo de hacer algo que valga la pena; los chismes de la Embajada y Cancillería y los de periodistas; el recuento que debe hacer para otros de su labor diplomática y el reclamo de cartas a sus amigos; la vida cotidiana dentro de un servicio exterior pésimamente organizado que exige al representante ejecutar tareas que van desde la intendencia hasta el más alto nivel del Estado; los recursos económicos siempre regateados por la Cancillería, las propias limitaciones materiales y la deuda contraída en Argentina; su falta

${ }^{13}$ La intención de don Alfonso fue, siempre, no mortificar a sus amigos con sus cuitas o, como le dice a Martín Luis Guzmán: "por no dar la lata", o a Estrada: "No quiero apenarlo con mis penas y males".

${ }^{14}$ Es conocida la carta dirigida a Genaro Estrada y Enrique Díez-Canedo en la que los nombra, en 1926, albaceas de su legado; el nombramiento procede de un reconocimiento: son sus amigos "en vida y en muerte" —aunque ambos se le adelantaron en la marcha última. Ahí, en la carta, Reyes deja ver su interés porque su obra literaria se conserve en forma unitaria. También deja ver que los aspectos personales y algunas tareas oficiales son "flecos sueltos". Cf. $O C$, t. 4, pp. 475 ss. 
de independencia, y, por último, mas no al final — pues aparecen como una constante a lo largo de 20 años—, sus estados de ánimo producidos por sus relaciones con algunas mujeres que oculta tras abreviaturas o referencias cifradas ${ }^{15}$. Junto a estos apuntes, quedan otros que él se resiste a mostrar por ser íntimos, y así lo reconoce:

Cuando me senté a escribir estas notas, estaba yo en ánimo combativo [indica Reyes en octubre de 1926 desde París]. Sólo que para mí el ánimo combativo — refrenado mil veces con dolor por los imperativos categóricos de la conducta y por mi firme propósito de conservar la serenidad lo más pobile- se resuelve en una reflexión, en un examen de ideas. No puedo negar que, en el primer instante, el largo atavismo de "cazador de hombres" (¿quién que sea humano puede jactarse de no tenerlo?), estremece mis nervios. No puedo negar que, un instante después, comienza esa lucha contra la fiera que todos llevamos dentro, lucha de la que salgo poco a poco cansado y con jaqueca. Sólo yo conozco los ratos de melancolía con que pago el derecho a sonreír de nuevo. Cada encuentro con la maldad es otra fatiga. Pero, al fin la educación de pensar va triunfando de todo ello, y mi pobre máquina humana cumple, como puede, el fin cosmogónico para el cual ha sido concebida: el de traducir en contemplación y en espíritu los estímulos naturales $(C L F$, t. 1, p. 43).

Si subrayamos la última línea, "traducir en contemplación y en espíritu los estímulos naturales", comprenderemos el sentido vital (tanto estético como sociopolítico) que anima toda la obra de Reyes; en su presentación a Ifigenia cruel (1923) hace explícita su apuesta única a la inteligencia y contra la irracionalidad. Sin embargo, cuando ésta lo cuestiona irrumpe una expresión que lo arrebata, sobrecoge y que explota tumultuosamente a partir de comentarios laterales y en apariencia insignificantes. Es obvio que

${ }^{15}$ El interesado en esta veta de la vida íntima de Reyes encontrará en su epistolario con Estrada los más abundantes, fragmentados y dispersos datos, todos elusivos. Con ganas de provocar la curiosidad cito un ejemplo fechado en octubre de 1928 —es de los más amplios y explícitos—: “¿Le dije que acabé con aquella historia de: «¿De qué estás hecho vos, muchachito mío?» Acabé y bien: es decir, quedando muy amigos, y hasta con cuartito puesto. Ahora tratamos de probar fortuna con la mejor tez morena que se ha visto en el Plata y sus riberas. Ya le contaré. Entre tanto, la vieja historia, ya corriendo por su cuenta y con su muchacho de antes al lado, ha recalado por aquí y, ya sin enredo (sabe mejor así) la hemos disfrutado regular y periódicamente. Es una excelente muchacha en el fondo, y merece bien de la patria" ( $C L F$, t. 2, pp. 161-162). Sobre este asunto véanse también mi artículo referido en n. 11 y el de F. Curiel, "AR en Río: arqueología de una pasión”, Sábado (suplemento de Unomásuno), 1990, núm. 670, 1-3. 
son asuntos que afectan su intimidad y que había venido rumiando, sin asimilarlos ni exteriorizarlos, y que rebasan su continencia a borbotones. Sólo bastaba el más leve gesto de reprobación de quien consideraba cercano. Esto ocurrió en raras ocasiones. El hombre aparece en toda su magnitud cuando se refiere a la opinión que los otros tenían de él, tema central en el epistolario. Reyes escribía de sí mismo: "yo vivo [tras] un muro de cristal". De esta preocupación destaco cuatro ejemplos.

El primer ejemplo data del 23 de febrero de 1926 y proviene de París. Días antes, su amigo Genaro le informa de ciertos rumores - a los que no debe dar crédito, insiste- sobre su supuesto mal desempeño como Embajador. Reyes responde con una larga y "muy confidencial" carta en la que pormenorizadamente explica cuáles han sido sus actividades — con tropiezos y aciertos—, sus emociones ante lo realizado y sus resultados; también describe a sus colegas antecesores y sus respectivas tareas, que critica y compara; concluye con una reconsideración sobre la importancia del cargo en París, la labor diplomática en tan compleja (y deseada) plaza y la maledicencia a la que están sujetos quienes desempeñan actividades públicas del gobierno mexicano en otros países. En suma, la carta es producto de un dolor: se dudó de su calidad como servidor público.

El segundo muestra un notable gesto de arrebato. Se encuentra en una larguísima carta dirigida (mas nunca enviada) a Martín Luis Guzmán, fechada en Río de Janeiro el 17 de mayo de 1930, día que cumplía 41 años. El origen es una dedicatoria de Guzmán manuscrita en La sombra del caudillo: "Para mi querido Alfonso Reyes cuyo nombre - de claros destellos- no merece figurar en el escalafón del bandidaje político que encabeza el traidor y asesino Plutarco Elías Calles". El dolido reclamo de don Alfonso avanza por el sendero de las descripciones autobiográficas centradas en sus concepciones de la política; son reconsideraciones ${ }^{16}$ que nos adentran en la más personal y profunda intimidad del hombre desgarrado, dolido, melancólico y reacio, para mostrar la entraña viva de su soledad — producida por los dolores de la violenta pérdida del padre y las luchas entre banderías políticas ni deseadas ni buscadas-; es el acto de mostrar la fragilidad quebradiza de una sensibilidad atrincherada a canto y lodo tras una gigantesca mampara de papel, de servicios y de bondad. Casi al final de la carta escribe Alfonso al amigo Martín:

${ }^{16}$ Las únicas —cabe la acotación- puntualmente claras y extensas dentro de la opera omnia del polígrafo, tan renuente a escribir sobre el asunto. 
¡Mire que me descubro sin tapujos, y le entrego, lealmente, todas mis pobres armas! -Y después: esta carta es para Ud. solo. Antes de que yo me atreviera a dejarla ver a los extraños, tendrá que llover mucho, y quizá sea mejor que antes llueva tierra sobre nosotros dos.

Esta carta también es producto de un dolor: su cercano y viejo amigo, con quien sentía una liga de lealtad y afecto recíprocos, dudó de su calidad moral.

El tercer ejemplo que exhibe el desahogo tumultuoso de Alfonso Reyes es el cuadernillo A vuelta de correo, fechado en Río de Janeiro en mayo de 1932. A diferencia de las dos anteriores, esta carta es pública y no está dirigida a ningún corresponsal en particular - aunque es su respuesta a la interpelación que el joven y entonces desconocido Héctor Pérez Martínez le hace desde $\mathrm{El} \mathrm{Na-}$ cional donde le reprocha su alejamiento y desvinculación de México. Reyes toma la ocasión para atar los cabos de una respuesta largamente meditada a la también larga serie de murmuraciones sobre su falta de nacionalismo, que habían agotado su paciencia. Aquí escribe sobre su propia vida pública, sus ideas de nación y nacionalismo en función de la literatura- $\mathrm{y}$, sobre todo, sus labores culturales derivadas de o encaminadas hacia su función diplomática. Asimismo, es un regaño público contra aquellos más preocupados en guerrillas pseudoliterarias y no ocupados en hacer obra literaria de calidad. Como en las dos anteriores, esta carta surge de un dolor: los jóvenes de su propio México, a los que supuestamente entrega su saber literario, lo desconocen y le reclaman lo que no es ni ha pretendido ser, guía para el porvenir.

El cuarto ejemplo es doble y se encuentra en las cartas que, en 1954, envió al cubano Jorge Mañach y, en 1940, al peruano Luis Alberto Sánchez, quienes en diferentes circunstancias le recriminan que "nunca ha sido peleador" y que su vida diplomática transcurrió plácida y confortablemente. Reyes moderado en su autoevaluación y sin los arrebatos del enojo que ambos comentarios le produjeron, describe a sus corresponsales su concepto de "combate" y su responsabilidad como diplomático: "Usted ha visto sólo el efecto exterior y no la trastienda". Remite a Mañach a su biografía - donde los rasgos de vendettas ocupaban un lugar sobresaliente, según explicó en Ifigenia cruel- y a Sánchez describe sus tareas y conflictos. Con ambos procura puntualizar malentendidos sobre un aspecto que le ha causado un prolongado dolor: nunca, ni propios ni ajenos, han comprendido su actividad pública y de "servicio nacional". 
En los cuatro casos, Alfonso Reyes respondió con extensas e intensas cartas escritas en un arranque de pasión; una noche de atropellado mecanografiar para, así, de un tirón, soltar toda la carga acumulada a lo largo de meses e incluso años. Son cuatro casos (a los que se podrían añadir otros tantos menos reveladores) en donde el escritor, efectivamente, busca expresar al otro su sentir y parecer. Sin embargo, sorprende que el borbotón original fuera rápidamente atenuado: en el caso de Estrada, con una carta posterior donde explica que aquélla (con el sentido de distancia implícito, aunque hayan transcurrido escasas veinticuatro horas entre una y otra) fue producto de un rato de ofuscación; en el de Guzmán, con el hecho de nunca enviarla y, en su lugar, mandar un agradecimiento insípido; en el de Pérez Martínez, con reflexiones finales orientadas hacia dimensiones universales, y en el de Mañach y Sánchez, acudiendo a corresponsales extranjeros con la casi certeza de que lo dicho no se sabría en México.

El freno impuesto a la rebelión de su intimidad se explica en el fragmento sobre el ánimo combativo citado párrafos atrás: encauzará su vitalidad — aunque dolida- hacia metas cristalizables en el bien del Otro; en algún momento, usó el concepto de sublimación. Por lo tanto, el espacio epistolar es, en este punto, el lugar y tiempo propiciatorios de la confrontación íntima; la reconsideración profesional ante presiones externas; el autoanálisis de su actividad literaria y de su repercusión entre los lectores y la nación, y, por último, de la creación del lector ideal a quien descubre su intimidad atropellada, pero que luego del desahogo reconoce de carne y hueso (por lo que asordina - e incluso ocultael aluvión íntimo).

\section{UN DEBATE, ENTRE LO PRIVADO Y LO PÚBLICO}

El cuarto aspecto del epistolario de Alfonso Reyes, el apunte apresurado recuperado dentro de una dimensión literaria, no es tan abundante. El escritor, cuya grafomanía es conocida, registraba todo en distintos medios, aunque los cuadernos y papeletas eran los más comunes junto con las cartas ${ }^{17}$. Las notas derivaban en, por ejemplo, la presentación del primer número de su Monterrey o de

${ }^{17}$ Reyes procuraba conservar copia al carbón de su correspondencia cuando era mecanografiada — hábito proveniente de las obligaciones del servicio diplomático y noción de la importancia de la obra accesoria, parafernárica. 
algunas narraciones de Vida y ficción, Quince presencias o Árbol de pólvora $(O C, \mathrm{t} .22)^{18}$. No obstante, son exiguas las ocasiones en que Reyes hace registros en su Diario o en su correspondencia de trabajos que florecerán en su obra literaria.

Dentro de la variedad y cantidad de notas, en su correspondencia con Genaro Estrada dejó escasa docena de apresuradas viñetas cuyo trazo descubre al retratista mordaz que se entretenía con esos ejercicios y que sabía que su corresponsal se los celebraría. Citaré dos porque no resisto la tentación. El primero es como una "instantánea" de cuerpo entero con paisaje:

El Cónsul, aburrido tema, pero es fuerza tocarlo [escribe desde Buenos Aires en diciembre de 1929]. Le he cantado a Ud. laudes de don Eduardo Soriano Bravo, a fin de que lo ascienda Ud. a Cónsul General, y se jubile con el mayor sueldo: lo merece quien ha dado lo mejor de su vida al servicio pestilente de las oficinas públicas, y en ellas se ha idiotizado. Ya está que se muere, con ese egoísmo de última hora que he visto florecer en [Francisco A.] Icaza, en Poulat, en todos los envenenados de burocracia cuando se acercan a la tumba. Sus arterias andan mal. Su organismo está diabético. Todavía anda ahí con su chilito parado, y ya tiene verdaderos gestos de mal de San Vito. Es muy honrado y laborioso. Confunde las iniciativas plausibles (como ésa del fondo de auxilio para los mexicanos náufragos que caen en estas tierras) con las tonterías más pueriles (como esa dichosa sociedad entre mexicanos para importar artículos de México, con dos mil y pico de pesos de capital, y no cincuenta mil como hizo decir él por los periódicos, y a la que todos hemos accedido por mera condescendencia). Ya está teóricamente peleado con el nuevo Agregado Comercial, Héctor Villatoro: acaso hay que dividir del todo estas oficinas y dejarle la exposición comercial sólo al Agregado - $\mathrm{O}$ sólo al Cónsul. Se guarda sus noticias, para lucirse con ellas ante Ud. ¡el pobre! En fin, comienza a caducar, pero cumple admirablemente con lo suyo, y creo que merece que lo asciendan y fusilen, digo, jubilen (CLF, t. 2, pp. 252-3).

El segundo ejemplo es, digamos, una postal:

Dije que era éste un clima de hipopótamos, tratando de describir este calor húmedo que sube del río, rueda por las calles, entra en las

18 Fernando Curiel ha realizado una pesquisa sobre el origen de las narraciones "El Samurai", "Calidad metálica” y "Análisis de una pasión” y ha encontrado en la correspondencia con Martín Luis Guzmán una de las fuentes de inspiración. Cf. Medias palabras..., pp. 183 ss. 
casas, se mete por los agujeros de la cabeza, humedece los muebles, chorrea en las paredes, afloja los nervios, lustra las pieles, relaja los músculos, disuelve los tendones, licua los cojones, "insipida" las pasiones, corroe lentamente el árbol de la vida, empaña los ojos y mata con lenta y bochornosa crueldad. El Plata es un río embrujado, color de caca. Sólo se le conoce otro antídoto verdadero: otro que se llama el Sena. Pero ¡ay!, el Sena está muy lejos, muy lejos —en donde se quedó nuestro corazón (CLF, t. 2, p. 117).

Sin embargo, a partir de los años treinta y en forma particular en su Diario, es común encontrar líneas sueltas que revelan un conflicto ante su más acendrada mortificación: escribir todo. En ellas se pregunta si apuntará esto o aquello para obra de creación o reflexión o para tareas de servicio o protocolo. Pronto, el Diario deviene en bitácora de diplomático y de hombre de letras, cuya vida pública es intensa y cuidadosa: entradas y salidas de correspondencia, visitas (de las que, eventualmente, recoge ideas vertidas en la conversación), actividades (de las que rescata rasgos, expresiones, datos, etc. $)^{19}$, y tanto más que lo colocan ante bifurcaciones en las que debe decidir para sí mismo qué de lo que escribe va para dónde (sus cuadernos y papeletas manuscritas son síntoma de su grafomanía). En su epistolario, prácticamente no existen los apuntes que derivarán en algunos de sus trabajos literarios, con la excepción de las cartas que envía a su "leal y verdadero" amigo Julio Torri desde París entre 1914 y 1915.

\section{EL ACERVO INDIVIDUAL Y LA HISTORIA CULTURAL}

En el común de los epistolarios casi siempre es uno de los corresponsales el que destaca ante los ojos del lector; son poco frecuentes aquellos donde ambos corresponsales guardan una relación de equilibrio y simetría; resultan raros en los que sobre el prestigio del protagonista prestigiado destaque un (o una) corresponsal desconocido y, como epistolarios excepcionales (aunque abundan en número), se encuentran esos donde se conservan sólo las cartas de uno de los corresponsales (el de mayor prestigio, por lo común) y, a contraluz la silueta del ausente adquiere di-

${ }^{19}$ Un ejemplo de calidad superlativa de estos registros que se transforman en trabajos más amplios es la magnífica crónica/informe La Conferencia Colombo-Peruana para el arreglo del incidente Leticia (1933-1934), en el Archivo de AR, México, 1947. Recogido en Misión diplomática, cit. supra, n. 12. 
mensiones humanas dignas de mejor suerte. Con el epistolario de Alfonso Reyes ocurre todo esto al mismo tiempo, de aquí su enorme valor humano e histórico.

Reyes ocupa el lugar protagónico de la reflexión en prácticamente todos los estudios desprendidos de su correspondencia. Sin embargo, el acervo informativo ha dado pie a estudios sobre sus corresponsales, época y lugares. Con esto, el eje central se ha trasladado para bien del epistolario mismo y de Reyes, aunque parezca una contradicción, a Válery Larbaud, Pedro Henríquez Ureña, Julio Torri, Genaro Estrada, Enrique Díez-Canedo, José Ortega y Gasset, Gabriela Mistral, Martín Luis Guzmán y muchos más de sus corresponsales. En otras palabras, para conocer una parte de ellos resulta indispensable indagar en la vida y actividades de don Alfonso.

La semblanza de Genaro Estrada, discernible a partir de sus cartas, posee gestos que subrayan la estrecha, íntima familiaridad de Alfonso Reyes. Esos gestos resaltan la mutua afinidad en la valoración del Hombre: "Me asustan la fealdad de los espíritus y la mugre de los corazones" —escribe Estrada—; y la reciprocidad en las sensibilidades literarias y artísticas: la educación del gusto - desde un vino, una figurilla de barro, un libro editado y encuadernado con rigor y belleza, hasta una pieza musical de Satie o Milhaud o un cuadro de Picasso-; las concepciones culturales y diplomáticas; la discreción en sus relaciones sentimentales o amorosas ${ }^{20}$; el cuidado escrupuloso en la administración de los recursos propios e institucionales; la generosidad en el reconocimiento del talento de otros y, por si fuera poco, la discreta ${ }^{21}$ manera de representarse a sí mismos ante los demás. Un rasgo ilustrativo: en noviembre de 1926, Estrada viaja a Nueva York y visita a José Juan Tablada, a quien encuentra enfermo; comenta Alfonso: "Vea — esto no lo diga a nadieyo estoy haciendo aquí sus crónicas, mientras él está en el hospital, pues sin crónicas le suprimirían el sueldo en El Universal".

${ }^{20}$ Hacia finales de enero de 1928, Genaro Estrada envía una carta cuyo último párrafo encierra una muy íntima descripción de su situación sentimental; sus palabras son puntuales y desvelan en forma elocuente la cercanía de ambos: "Mi chatita ya estaba anuente en casarse conmigo en abril. Entonces principié a hablar del caso en casa. ¡Camará! Pues ha de saber usted, si no se lo he dicho, que mi madre estuvo casada con mi padre, sólo seis meses. A los seis meses del matrimonio murió mi padre. Seis meses después de la muerte de mi padre, yo nací. Mi madre ha vivido siempre conmigo. No volvió a casarse, no tuvo más afecto íntimo. Entonces - entonces- cada vez que hablo de matrimonio la cosa se pone mal. Ni siquiera se imagina eso. El caso de los hijos únicos. Yo voy cargando con mi pequeña tragedia. ¿Pequeña?...” ( $C L F$, t. 2, p. 104).

${ }^{21}$ En el sentido que Gracián otorga al concepto. 
La de Estrada es, en apariencia, una imagen simple. En los tempranos años del diez, el joven Genaro se ofrece sin cortapisa: "Mande en lo que guste. No importa que esté yo muy ocupado, porque me doy tiempo para todo". Hasta momentos previos a su muerte en 1937 cumplió con su generoso ofrecimiento, que se tradujo a lo largo de veinte años en buscar el apoyo para que escritores y pintores mexicanos contaran con una difusión nacional e internacional - a lo que Reyes contribuía con sus relaciones amistosas-; allegar a Alfonso todo lo disponible para la edición de las Obras completas de Amado Nervo - lo que exigió pesquisas hemerográficas y transcripciones, costeadas por Estrada-; servir de enlace y mediador en asuntos oficiales y familiares, sobre todo cuando los chismes de Cancillería socavaban la estabilidad de Reyes o cuando su situación familiar se volvía difícil; cumplir la labor de equilibrado y suspicaz informante sobre las características de la vida literaria, editorial y política (Boletín genariano, como lo califica); normar los movimientos diplomáticos de su subalterno mediante sutiles sugerencias, como enviar una carta a Sutano, personarse con Perengano, comentar al paso ante Mengano o hacer caso omiso de cuentas o cuentos, y así hasta completar la semblanza de un hombre cuya amistad, bondad y voluntad de servicio estaban primero. Con palabras de Estrada sobre sí mismo: "Tengo, y ésta es la primera vez que lo digo a alguien, un corazón profundamente acogedor, instantáneo y permanente para la simpatía y enemigo implacable del odio y del rencor".

Otra parte de la semblanza de Genaro Estrada se dibuja cuando se descubre ante su "confesor laico, caja fuerte y archivo secreto", como califica a Alfonso Reyes. Los asuntos de Cancillería vistos a distancia parecen menores y hasta insignificantes, pero entonces (hacia 1923-24, cuando las fricciones de la sucesión presidencial) eran delicados y así los comunica a su colega, a quien expone pormenores indispensables para valorar circunstancias -intrigas palaciegas-, personas — recomendadas por el Presidente- y conductas — que los pueden afectar a ambos. Fragmentada y dispersa, esa información permite husmear en la política de Palacio. No es gran cosa, pero sí se alcanzan a percibir ciertos movimientos de Estrada en la Cancillería, como el manejo de información indispensable para normar opiniones y orientar decisiones redundantes en provecho del Estado ${ }^{22}$. Reyes escri-

${ }^{22}$ Un ejemplo de la discreción oficial: "Oh qué amenidad y cuál portento de carta No. 8 [escribe Estrada en enero de 1928]. Se la leeré, mañana, viernes, 
be la meta y Estrada la suscribe: "Cuando hablo de éxito... me refiero... al crédito moral de México". Escasos, destacan tres o cuatro consejos de la superioridad dirigidos al colega cuando muestra gestos de flaqueza ${ }^{23}$. Por último, en la tesitura del consejo y de la llamada de atención, sobresale uno enviado desde Madrid, fechado significativamente el 25 de diciembre de 1932, en el que Genaro resume su credo, sin duda compartido por Alfonso - quien por entonces atravesaba una crisis de inseguridad "laboral":

No, mil veces no, ya no piense usted en pobretear con honra en el extranjero, ¡no! Nuestro sitio, bueno o malo, está en México y allá debemos hacer cuanto podamos hacer, nuestro propio trabajo y el trabajo que pueda beneficiar a México; pero allá. Yo he venido aquí, Alfonso, con gusto porque vine a España y por deber, para no negarme cuando siempre he recibido acogimiento y buen trato. Pero una vez cumplido este deber, dentro de un plazo breve que yo mismo me he fijado - el indispensable para un precario arreglo económico- regresaré a México, a trabajar allá, que desde siempre tengo en abandono mis libros, y mis papeles, y mis proyectos. Si la fortuna me permite regresar a Europa por mi cuenta, siempre tendré placer en volver. Pero no saquemos el cuerpo a nuestro deber fundamental, que está en México. Recuerde usted, Alfonso, que hasta en los casos más universales - en las letras, en la política, en la guerra- la acción ha sido local y el tiempo se ha encargado de darle aspectos generales. Se puede servir, aunque sea muy modestamente, al mundo y a nuestros semejantes, sirviendo a México o en México. Y además, tendrían razón las gentes que en el curso del tiempo cargaran las culpas a los indiferentes o tímidos. Mientras que de cuando en cuando aparecen los fatales "providenciales" — flor de psicología política de las dictaduras iberoamericanas- una muche-

al Presidente [Calles]. Sí, no asustarse, se la leeré y la comentaré. Siempre, ya lo sabe usted, lo he tratado con amistad de amigos y camaradas; pero esto no lo quiero decir a las gentes para que no vayan a creer que soy político, ni igualado. El caso es que, últimamente, mientras se va acortando el período, en lugar de sacarle el bulto, como hacen las gentes que yo me sé, me acerco más al bulto y él, que es muy franco y cordial conmigo y me confía indiscreciones y hablamos de cosas de confianza, se ha hecho más amigo y hablamos a cuerno limpio" (CLF, t. 2. p. 103).

${ }^{23}$ Por ejemplo: "No se queme usted la vida con los «pendejos», no se la queme [escribe «G» al «Cherísimo Alifonsus» en abril de 1925]. Es inútil tratar de eliminarlos y aun siquiera de domesticarlos. La «mala leche» — como la llaman los españoles- es inmortal. A veces hasta resulta conveniente o útil que digan ligerezas de uno. Eso da fuerza y biografía. «Por lo demás» usted ya tiene una personalidad definida y definitiva y pueden pasarse por debajo, así con todas las tonterías" (CLF, t. 1, p. 315). 
dumbre de voraces lo domina todo. Los tímidos retroceden ante su calculada gritería. Pero ¿es posible que tales cosas nunca se reformen o desaparezcan? ( $C L F$, t. 3, pp. 332-333).

\section{LA LENGUA COMO DIMENSIÓN UNIVERSAL}

El epistolario conjunto de Alfonso Reyes integra la más extensa e intensa urdimbre informativa disponible entre los hombres de letras o políticos hispanoamericanos. Desde el temprano 1907 y hasta su muerte en 1959, y desde los escritores de mayor prestigio y trascendencia hasta el hombre de letras hispanoamericano más joven y desconocido, el torrente epistolar teje, en su abstracción y más allá de los protagonistas particulares, los hilos de una historia literaria centrada en una cualidad rectora: lo noción civilizadora de la cultura, cifrada en la lengua escrita.

Tras el esfuerzo que significa hacer una substracción de la catarata de datos informativos del más variado tipo, la correspondencia cruzada entre Alfonso Reyes y su centenar de corresponsales dibuja la trama de una historia básica: la construcción de la idea de Hispanoamérica, sobre la que concurrirán y de la que se desprenderán, por ejemplo, tareas de difusión, creación y reflexión culturales tan abarcadoras como las emprendidas por los hermanos García Calderón en París antes de 1914 o las de Silva Herzog en México a partir de los cuarenta, y en las que Reyes cumple una valiosa labor de enlace y promoción; tareas político-diplomáticas en las que carga el acento en las culturales, pues reconoce que el cimiento más sólido que puedan tener las relaciones diplomáticas de los países del continente son las de la inteligencia y, sobre éstas, resultará fácil construir cualquier otra relación; y tareas de vinculación personal —de algún modo hay que denominarlas-, pues él procuró establecer lazos de sus corresponsales entre sí, con lo que logró anudar los hilos de la red de amistades y alianzas.

Las virtudes que se desprenden del epistolario completo corroboran un propósito: la voluntad civilizadora que lo anima en sus oficios y ejercicios. Esta cualidad no es privativa de Alfonso Reyes, sino parte de toda una atmósfera identificable en la generación hispanoamericana de 1900 (en la que estaría incluido el Ateneo de la Juventud) o, en cierto modo, de la Generación del 98 español (con la que él compartió mucho de sus quehaceres y reflexiones durante su estancia en España). Por tanto, el epistolario 
conjunto permite identificar los medios y recursos, las personas más activas, los países participantes, los momentos particulares o épocas conjuntas, los alcances y riesgos de decisiones e incluso sus resultados, los obstáculos y modos de librarlos, los entusiasmos e incertidumbres y, así, hasta dibujar las líneas abstractas indispensables para civilizar a los hombres del continente (no indico "países" ni "pueblos" debido a que estos conceptos son raros dentro del epistolario).

La herencia del Modernismo - y en forma directa de Darío, Rodó y Nervo sobre Reyes, como figuras preponderantes- marcó en don Alfonso una distinción: por encima de los Estados nacionales y sus gobiernos están los hombres del continente y su lengua. En otras palabras, Darío cifró para Hispanoamérica la distinción de ser tierra de generales y poetas; aquéllos hábiles en las tareas prácticas y torpes en el uso de la imaginación, y éstos dueños de las ideas y de las palabras para expresarlas. Lo segundo permanecerá, mejor aun, se adelantará a lo primero. Reyes también creía en eso - y la correspondencia con Estrada y con Henríquez Ureña es paradigmática - y su diplomacia estaba enfocada hacia lo abstracto, básico y perenne, como ilustra su Código de la paz, elaborado junto con Manuel J. Sierra en la primera mitad de los años treinta. Ahí proponía la creación de una institución equivalente a la Corte Internacional de Justicia, pero dedicada sólo a los países hispanoamericanos.

Junto a la urdimbre pública identificada en los afanes civilizadores se teje la urdimbre privada, siempre soslayada y mostrada como al acaso o en contadísimos y catárticos torrentes. Ernesto Mejía Sánchez y Alfonso Rangel Guerra, por ejemplo, han mostrado cómo la urdimbre privada del diario y el epistolario está estrechamente ligada con la creación literaria; registros nimios, pero abundantes, y apuntes primarios anotados a vuelapluma adquieren su real dimensión como poesía y ensayos. Es decir, Reyes confiaba al amigo distante o al cuaderno cotidiano las ideas ya nacidas o en gestación; más aun, como ilustra la correspondencia con Martín Luis Guzmán —según demostró Fernando Curiel—, en la espontaneidad de la "conversación a distancia" Reyes encuentra la base que germinará en narraciones o reflexiones.

Consecuentemente, no obstante lo tangencial del registro, en esa urdimbre se puede identificar una clara secuencia de lazos afectivos y pasionales, de notas fragmentadísimas y reflexiones relativamente acabadas, y de divertimientos literarios y bocetos para desarrollar. En suma, lo circunstancial de la fecha y el lugar (da- 
tos que nunca olvida apuntar, de aquí que se conviertan en verdaderas bitácoras), permiten identificar los lazos que atan la creación artística con la biografía del hombre; la universalidad de uno y la particularidad del otro. Alfonso Reyes, experto en estos menesteres, admitía que en el estudio de las letras siempre es útil contar con datos de la vida material del artista para valorar su obra. Entre los datos y la obra aparece el sentido de una vida.

Sin esto, por ejemplo, resultaría por demás complejo poder ponderar el conflicto padecido por Reyes y condensado por Cervantes en el Quijote. La confrontación entre las armas y las letras, entre el hombre comprometido con su "servicio obligatorio" y el artista. La generación hispanoamericana de 1900 con la que don Alfonso está estrechamente hermanado, distingue entre generales y poetas y, en última instancia, reconoce la necesidad de asumir la responsabilidad de ambas tareas: sacrificar al artista en aras del bien colectivo encabezado por el general o asumirse como general que encabeza un ejército de letrados. Sin embargo, Reyes, con algunos más, sufre un íntimo conflicto en la sola disyunción: hombre de gobierno $o$ escritor, héroe cívico $o$ artista. Con abundantes gestos menores, el epistolario y el Diario dan cuenta del conflicto, que no fue privativo de don Alfonso ni de los años en que le tocó vivir.

Por último, la noción del "nosotros" tan acusada en su epistolario con Pedro Henríquez Ureña y tan subrayada en un famoso artículo de igual nombre en la revista Nosotros (marzo de 1914), sólo es uno de los muchos ragos ilustrativos del autorreconocimiento (y de la autolegitimación, valga acotar) generacional como cimiento para el porvenir. En una dimensión literaria, metafórica, el epistolario, el Diario y sobre todo la Obra completa, muestran la compulsión de Alfonso Reyes por llenar un vacío íntimo que, extrapolado sobre la dimensión del imaginario colectivo, conduce a la voluntad para llenar un vacío cultural nacional y continental. También, ese "nosotros" remite a un protagonismo que, junto a Genaro Estrada, se asume con discreción. Se saben y se reconocen artífices de un concepto de política fundado en normas universales (v. gr. Doctrina Estrada o Código de la paz). Finalmente, la noción de "nosotros", ligada a la voluntad civilizadora, cristaliza en la virtual conjunción de la antípoda: el héroe cívico está metamorfoseado en la obra del escritor y el artista trascenderá mediante sus aportes cívicos.

Víctor Díaz Arciniega 